\title{
Description of atmospheric freeze-drying of brown seaweeds (Saccherina Latissima) with respect to thermal properties and phase transitions
}

\author{
Tolstorebrov, I. ${ }^{\text {a*; }}$ Eikevik, T. M. ${ }^{\text {a }}$ Petrova, I. ${ }^{\text {a }}$; Bantle, M. ${ }^{b}$ \\ ${ }^{a}$ Department of Energy and Process Engineering, Norwegian University of Science and Technology, \\ NO-7049 Trondheim, Norway, Tel.: +47 73593742, \\ ${ }^{\mathrm{b}}$ Sintef Energy Research, Trondheim Norway \\ *E-mail of the corresponding author: ignat.tolstorebrov@ntnu.no
}

\begin{abstract}
Thermal properties of brown seaweeds (Saccharina latissima) were determined using DSC technique in the temperature range between -150.0 and $50.0^{\circ} \mathrm{C}$. The following phase transitions were detected: glass transitions, incipient point of ice melting and freezing point. The ice content and amount of unfrozen water was detected by analysis of the melting peak. The ice content reduction in the product was predicted for different moisture contents and temperatures for atmospheric freeze-drying process.
\end{abstract}

Keywords: brown seaweeds, ice fraction, freeze-drying, glass transition 


\section{Introduction}

Most of the seaweeds, which are used for food purpose in Norway belong to aquaculture products, when hatching, growth and harvesting is controlled continuously. The harvesting season occupies approximately 2 weeks to provide the best quality of the seaweed's blades. The processing technology requires immediate processing of raw seaweeds to ensure production of sustainable and high quality product. Due to high quantities of raw seaweeds during harvesting the immediate freezing is applied to prevent deterioration. However, drying is the common way to preserve food products like seaweed and most of the seaweeds are sold in a dried form ${ }^{[1]}$. Solar and natural drying of seaweeds is a costeffective method. At the same time climate conditions can result in a high final moisture content in dried product ${ }^{[2]}$ due to high moisture absorption ability ${ }^{[3]}$, aslo, the process 5 or 7 days ${ }^{[4]}$. Due to this, the producers of Saccharina Latissima consider the atmospheric freezedrying process as the most reliable for the given processing condition. Design of equipment and adjustment of the processing parameters is complicated without knowledge of thermal phase transitions at freezing temperatures. The study discusses the thermal properties of seaweeds and seaweed's mucus and their influence on the atmospheric freeze-drying process. The investigation of seaweeds mucus was introduced due to high amount this substance on the blades, which provide stickness of the particles (blades) during atmospheric freeze-drying.

\section{Materials and Methods}

\subsection{Characterization of raw material}

The brown algae Saccharina latissima, which is commonly referred as kelp (Sugar kelp or kombu) was used for the experiments. The seaweeds was cultivated for one year in an aquaculture farm, which is situated in Sør-Trøndelag (Norway). Harvesting season was 15 days in May 2017 to maintain the best quality of the seaweeds and avoid high amount of biofouling. The seaweed was harvested into nets $(75-150 \mathrm{~kg})$. The nets were buffered in the seawater at the farm where they were kept in refrigerated seawater $\left(-1.0^{\circ} \mathrm{C}\right)$ for 1 week before freezing. Then the seaweed was weighed out and packed inside vacuum bags with high barrier properties $\left(2.0 \mathrm{~kg}\right.$ each). Freezing was at $-46{ }^{\circ} \mathrm{C}$ until temperature in the center of the bag reached $-18.0^{\circ} \mathrm{C}$. After freezing the bags were packed in cardboard boxes, put on pallets and placed in freeze storage at $-18{ }^{\circ} \mathrm{C}$. The kelp was delivered in a frozen state by the supplier (June 2017). Chemical composition of the aquaculture seaweeds is given in the Table 1. Protein content of the seaweeds was determined at $11.2 \%$ d.b., which was in a common range for brown seaweeds between 3.0 and $15.0 \%{ }^{[5]}$. The aquaculture seaweeds form Damariscotta bay (USA) had a protein content of $6.87 \%$ d.b. ${ }^{[6]}$, which was in the range (between 9.9 and $7.6 \%$ d.b.) of the previously obtained results for wild sugar kelp form Scotland, Isle of Seil ${ }^{[7]}$. 
Table 1. Chemical composition of Saccharina latissima at harvesting season (analysis performed by accredited analytical laboratory Kystlab preBIO, Frøya, Norway).

\begin{tabular}{lcll}
\hline Chemical composition & \%, d.b. & Minerals, $\mathbf{~ m g / k g ~ d . b .}$ \\
\hline Proteins & 11.2 & Potassium & 84000 \\
\hline Fats & 2.9 & Sodium & 52000 \\
\hline Carbohydrates & 55.3 & Calcium & 10000 \\
\hline \multicolumn{1}{c}{ Incl. Dietary fiber } & 46.6 & Magnesium & 7500 \\
\hline Ash & 37.9 & Sulfur & 7300 \\
\hline \multicolumn{1}{r}{ Incl. Salt $(\mathrm{NaCl})$} & 14.6 & Iodine & 3670 \\
\hline Water & 900.0 & Phosphrus & 1700 \\
\hline
\end{tabular}

\subsection{DSC analysis}

The DSC analysis was done with a DSC Q 2000 (TA instruments, USA) equipped with a Liquid Nitrogen Cooling System. The heat capacity was calibrated with a sapphire in the range between -150.0 and $180.0{ }^{\circ} \mathrm{C}$. Helium was chosen as a purge gas at $25 \mathrm{~mL} / \mathrm{min}$, according to TA's instrument recommendations. The reference sample was an empty hermetically sealed aluminum pan.

In this study, the small particles of seaweed blades were used for DSC. The samples with masses between $13.0 \mathrm{mg}$ and $20.0 \mathrm{mg}$ were placed into aluminum pans with hermetic lids. The pans were sealed with a Tzero® DSC Sample Encapsulation Press (TA Instruments, USA). The pans were placed by an autosampler into the DSC cell. Samples were cooled and equilibrated for 5 minutes at $-150.0{ }^{\circ} \mathrm{C}$; the cooling rate was $10.0{ }^{\circ} \mathrm{C} / \mathrm{min}$. The annealing procedure was applied at $-50.0{ }^{\circ} \mathrm{C}$. This was done to avoid cold crystallization during scanning. Then the samples were heated up to $50.0{ }^{\circ} \mathrm{C}$ (application of higher temperatures was not effective due to evaporation of moisture) with the heating rate of 10.0 ${ }^{\circ} \mathrm{C} / \mathrm{min}$.

\subsection{Determination of glass transition}

The glass transition was determined with TA Universal Analysis 2000 version 4.5A software (TA instruments, USA). The glass transition is characterized with the following parameters: the onset, end and inflection points. It should be noted, that the glass transition in seaweeds with high moisture content is relatively weak. Thus, the inflection point was determined as a negative peak of the derived heat flow curve ${ }^{[8]}$.

\subsection{Determination of end of freezing and initial freezing point}

The onset of ice melting (or end of freezing point), was determined by analyzing the DSC heating curve. The freezing point was estimated as a minimum value of the ice melting endothermic peak on the DSC heat flow curve. 


\subsection{Determination of ice fraction and unfreezable water}

The amount of unfreezable water and ice fraction was detected by the DSC melting curve analysis. The DSC melting peaks were integrated with the sigmoidal tangent baseline function from the onset of ice melting point. The ice fraction was determined as a ratio of melting energy to latent heat of fusion of pure ice. As soon as melting energy of ice is a function of temperature, the empirical equation suggested by Riedel ${ }^{[9]}$ was used for correction of obtained values. The amount of unfreezable water was obtained as the difference between the total water fraction in the product and the ice fraction.

\subsection{Statistical analysis}

The analysis of variance (ANOVA: single test and two-factor test with replication) was applied to analyze the obtained data. The difference was considered significant at $\mathrm{p}<0.05$. All the experimental points were done in six parallels, except of desorption isotherm determination, where each point represents a single experiment.

A regression analysis was done with a software DataFit 8.1 program (Oakdale Engineering). The quality of the regression was evaluated with the following parameters: FRatio, Prob(F) and $\mathrm{R}^{2}$. F-Ratio is the ratio of the mean regression sum of the squares divided by the mean error sum of the squares. Prob(F) is the probability that the null hypothesis is true. $\mathrm{R}^{2}$ is the coefficient of multiple determinations. The standard deviation is introduced in the brackets after the values given in the text.

\section{Results and Discussion}

\subsection{Glass transition phenomena in raw seaweeds and seaweed mucus}

Two type of material were investigated: seaweed's blades and seaweeds mucus. The DSC investigation revealed two glass transitions at the ultra-low temperature region at 84.77(1.35) and $-62.14(0.46){ }^{\circ} \mathrm{C}$ for seaweed's blades and at $-74.44(2.15)$ and $-55.02(0.48)$ ${ }^{\circ} \mathrm{C}$ for mucus. It should be noted, that the glass transition phenomena was weak due to high amount of water fraction in the product, however, the negative peak was clearly observed on the derived heat flow curve. In previous study of Sappati et. al., ${ }^{[6]}$ only one glass transition event was determined.

The occurrence of two glass transition refer to different fractions of unfreezable water, which forms independent maximal freeze concentrated solutions. Each of the solution has unique point of glass transition. The presence of more than one glass transition for lowmoisture foods, which contain carbohydrates and proteins, was reported before ${ }^{[10]}$. It is explained by transitions of blends and thermal history of the sample. Also, immiscible compounds which forms individual maximal-freeze concentrations can cause the several 
glass transitions, however, it is not a strict rule ${ }^{[11]}$. As a conclusion, one can state that the second order phase transition will not influence on the

\subsection{End of freezing and melting peaks of raw seaweeds and seaweed mucus}

The so-called "end of freezing" is an equivalent of the incipient point of ice melting on DSC heat flow curve considering equilibrium freezing process. This point can be found on heat flow curve derived by time. The detailed information of the method available in Tolstorebrov et., al. ${ }^{[12]}$. Seaweeds blades and mucus showed different end of freezing point $-52.23(1.61)$ and $-42.1(0.65){ }^{\circ} \mathrm{C}$. This information was used for derivation of melting peak for obtaining melting energy.

The melting endotherm consisted of two peaks for both seaweed blades and mucus, (Fig, 1). The low temperature narrow melting peak reflects crystallization of salts (mostly $N a C L$ ), the peak was integrated in the melting peak of ice, which occupied the temperature diapason between end of freezing and initial freezing point. Initial freezing point was determined as extremum of the ice melting peak -1.31(0.06) and $-1.31(0.24){ }^{\circ} \mathrm{C}$ for seaweed blades and mucus respectively.

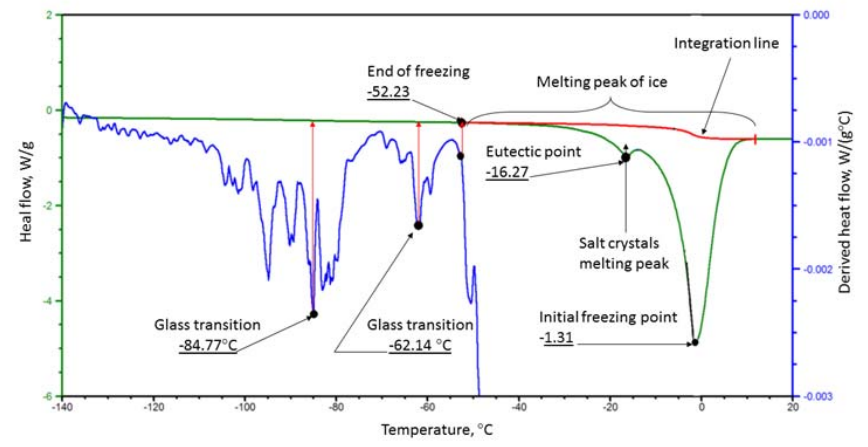

Fig. 1. Thermal transitions in seaweed's blade: heat flow curve and derived by temperature heat flow curve.

Analysis of the melting peak revealed that significant part of moisture was in a crystalline form at freezing temperatures. The value of melting energy was found at 271.2(5.0) and 259.35(0.95) for seaweeds blades and mucus respectively. It is remarkable, that the highest amount of ice was formed in seaweed's blades while the highest moisture content was determined for mucus $91.97(0.6)$ vs. 88.67(0.6) \% w.b. Relatively high initial freezing point and ice content create good conditions for atmospheric freeze-drying process.

\subsection{Ice content and unfreezable water in seaweed's blades and mucus}

Seaweed blades showed $10.39(0.59) \%$ w.b. of unfreezable water, while the value of $17.02(1.35) \%$ w.b. was determined for mucus. The value of unfreezable water in mucus is 
relatively high when compares with other foods. This will result in a low content of solids in the maximal freeze concentration solution, which is formed during transition of water into ice. At the end point of freezing the freeze consternation was at 52.13(0.45) and $31.14(1.05) \%$ w.b. for seaweed's blades and mucus respectively.

Both types of samples showed a significant increasing of ice content in vicinity of initial freezing point, (Fig. 2), which is typical for seafood products of a high moisture content. The concentration of ice reached 63.9 and $66.2 \%$ w.b. at $-10.0^{\circ} \mathrm{C}$ and $33.39(0.42)$ and 34.04(0.9) at $-5.0{ }^{\circ} \mathrm{C}$ for seaweed blades and mucus respectively. These temperature diapason is considered to be the most common for atmospheric freeze-drying process application $^{[13]}$. The model of Schwartzberg ${ }^{[14]}$ was used to describe the process of ice formation.

The model accuracy were weak for seaweed blades due to the influence of mucus, while the quality of the model for mucus was relatively good $\left(\mathrm{R}^{2}>0.98, \mathrm{~F}(\right.$ Ration $\left.)>500, \operatorname{Prob}(\mathrm{F})=0\right)$.

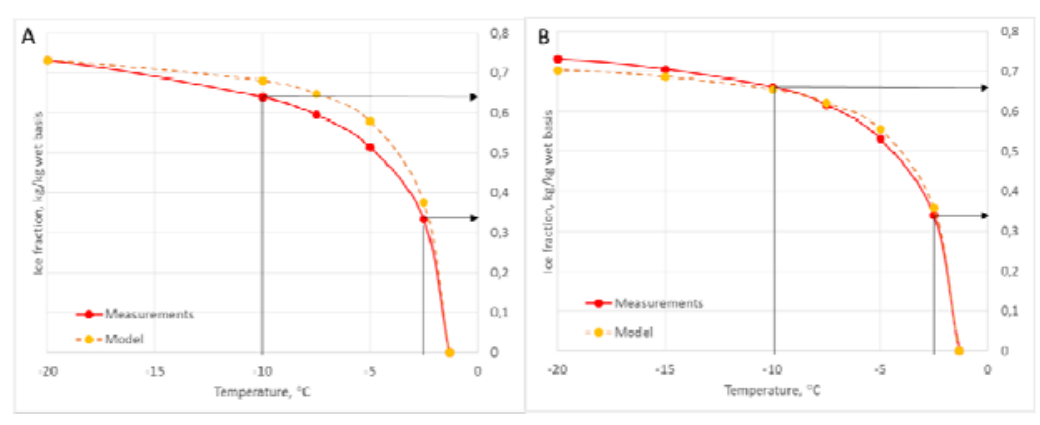

Fig.2. Ice fraction in seaweeds (left) and mucus(right) with respect to temperature. The diagrams introduces experimental data and models.

One can notice that the values of ice content are not so different in the seaweed blade and mucus (for the same temperature intervals). At the same time, the concentration of solids ( $\mathrm{kg} / \mathrm{kg}$ w.b.) is low and varies significantly between the samples, which influence on the ice development during the atmospheric freeze-drying process. The data, obtained in this chapter is essential for prediction of ice content during the freez-drying process.

\subsection{Development of ice content with respect to total moisture content}

The ice content in a product is in equilibrium with freeze concentrated solution and temperature: decreasing of the temperature results in the increasing of ice content, while increasing of solids in a freeze concentrated solution provoke the ice melting. Classical explanation of atmospheric freeze-drying process includes sublimation of ice and formation of dry front in the product. However, this situation will not occur in the case of seaweeds, 
as soon as ice crystals will be covered by the layer of unfrozen brine, which include dissolved salt ion, carbohydrates (mannitol) and proteins. Obviously, evaporation of unfrozen brine will be predominant. This will increase the concentration of solids in the concentrated solution and the ice crystals will melt.

Fig. 3 introduces the decreasing of ice content with respect to totl moisture content. The ice melting ocuurs much more rapidly for mucus. Thus, the surface of the product will show the different drying behavior when compared with the whole blades. The application of temperatures below the initial freezing point is suitable only at a high moisture content in the product, when the moisture content ( $\mathrm{kg} / \mathrm{kg} \mathrm{w.b}$.) decreases, for example, to $76.0 \%$ (seaweeds) and $84.0 \%$ mucus at $-5.0{ }^{\circ} \mathrm{C}$ the application of freezing temperatures is not required, as soon as the process can not be considered as a freeze-drying.
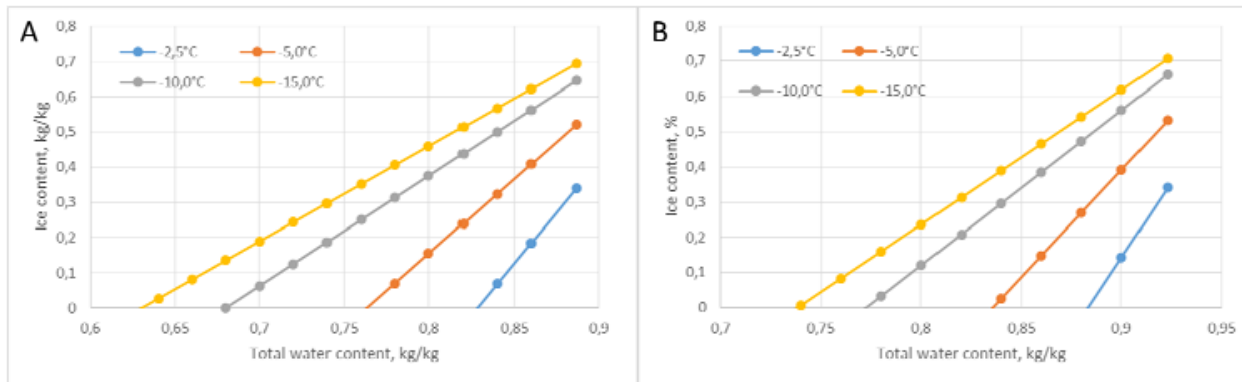

Fig. 3. Equilibrium ice fraction in seaweeds(left) and mucus(right) for different atmospheric-freeze drying temperatures (with respect to total water content)

Diagram on the figure 3 can be used for determination the desired freeze-drying temperatures. It should be noted, that the real content of ice will be a function of weight ratio: blade weight to mucus weigt.

\section{Conclusions}

The two glass transition phenomena was detected at the ultra-low temperature region at 84.77(1.35) and $-62.14(0.46){ }^{\circ} \mathrm{C}$ for seaweed's blades and at $-74.44(2.15)$ and $-55.02(0.48)$ for mucus. Seaweeds blades and mucus showed different end of freezing point $-52.23(1.61)$ and $-42.1(0.65){ }^{\circ} \mathrm{C}$. The unfreezable water content in seaweed blades was at $10.39(0.59) \%$ w.b., while the value of $17.02(1.35) \%$ w.b. was determined for mucus. Due to this the maximal freeze concentration was at 52.13(0.45) and 31.14(1.05) \% solids w.b. for seaweed's blades and mucus respectively. The aplucation of atmospheric freeze-drying process is limited by theses values: full ice melting when the total moisture content is still high (during drying process). 
Description of atmospheric freeze-drying of brown seaweeds (Saccherina Latissima) with respect to thermal properties and phase transitions

\section{Acknowledgement}

Mobility of the scientists from Murmansk State Technical University was provided by financial support of SIU, High North Programme 2015 (HNP-2015/10053)

\section{References}

[1] Forster, J.; Radulovich, R.; Chapter 11 - Seaweed and food security. In Seaweed Sustainability; D.J. Troy, Eds., Academic Press: San Diego, 2015; 289-313

[2] Phang, H.-K.; Chu, C.-M.; Kumaresan, S.; Rahman, M.M.; Yasir, S.M. Preliminary study of seaweed drying under a shade and in a natural draft solar dryer. International Journal of Science and Engineering 2015, 8(1), 10-14.

[3] Lemus, R.A.; Pérez, M.; Andrés, A.; Roco, T.; Tello, C.M.; Vega, A. Kinetic study of dehydration and desorption isotherms of red alga Gracilaria. LWT - Food Science and Technology 2008, 41(9), 1592-1599.

[4] Fudholi, A.; Othman, M.Y.; Ruslan, M.H.; Yahya, M.; Zaharim, A.; Sopian, K. Design and testing of solar dryer for drying kinetics of seaweed in Malaysia. In Proceedings of the 4th WSEAS international conference on Energy and Development, Environment and Biomedicine, Corfu Island, Greece, August 24-26, 2011; 119-124.

[5] Fleurence, J. Seaweed proteins. Trends in Food Science \& Technology 1999, 10(1), 25-28.

[6] Sappati, P.K.; Nayak, B.; van Walsum, G.P. Effect of glass transition on the shrinkage of sugar kelp (Saccharina latissima) during hot air convective drying. Journal of Food Engineering 2017, 210, 50-61.

[7] Schiener, P.; Black, K.D.; Stanley, M.S.; Green, D.H. The seasonal variation in the chemical composition of the kelp species Laminaria digitata, Laminaria hyperborea, Saccharina latissima and Alaria esculenta. Journal of Applied Phycology 2015, 27(1), 363-373.

[8] Tolstorebrov, I.; Eikevik, T.M.; Bantle, M. Thermal Phase Transitions and Mechanical Characterization of Atlantic Cod Muscles at Low and Ultra-low Temperatures. Journal of Food Engineering 2014, 128, 111-118.

[9] Riedel, L. Eine formel zur berechnung der enthalpie fettarmer lebensmittel in abha ${ }^{\circ}$ gigkeit von wassergehalt und temperatur. Bureau of Standards Journal of Research 1978, 5, 129-133.

[10] Figueroa, Y.; Guevara, M.; Perez, A.; Cova, A.; Sandoval, A.J.; Muller, A.J. Effect of sugar addition on glass transition temperatures of cassava starch with low to intermediate moisture contents. Carbohydrate Polymers 2016, 146, 231-237.

[11] Gaikwad, A.N.; Wood, E.R.; Ngai, T.; Lodge, T.P. Two Calorimetric Glass Transitions in Miscible Blends Containing Poly(ethylene oxide). Macromolecules 2008, 41(7), 2502-2508.

[12] Tolstorebrov, I.; Eikevik, T.M.; Bantle, M. A DSC study of phase transition in muscle and oil of the main commercial fish species from the North-Atlantic. Food Research International 2014, 55, 303-310.

[13] Claussen, I.C.; Ustad, T.S.; Strømmen, I.; Walde, P.M. Atmospheric Freeze DryingA Review. Drying Technology 2007, 25(6), 947-957.

[14] Schwartzberg, H.G. Effective heat capacities for the freezing and thawing of food. Journal of Food Science 1976, 41(1), 152-156. 